\title{
Kinetics and Thermochemistry of the
}

\section{Addition of Atomic Chlorine to Acetylene}

\author{
Yide Gao, I.M. Alecu, P-C. Hsieh, A. McLeod, Chris \\ McLeod, Maxwell Jones and Paul Marshall* \\ University of North Texas, Department of Chemistry, PO Box 305070, \\ Denton, Texas 76203-5070, USA \\ *e-mail marshall@unt.edu, fax (940) 565-4318
}

Colloquium: Reaction Kinetics

Word count (Method 1)

Main text: 2560 words

Equations: 281 words

References: 577 words

Table 1: $\quad 91$ words

Table 2: 243 words

Fig. 1: $\quad 163$ words

Fig. 2: 163 words

Fig. 3: 160 words

Fig. 4: $\quad 157$ words

Fig. 5: $\quad 155$ words

Fig. 6: $\quad 676$ words

Fig. 7: $\quad 145$ words

Fig. 8: 176 words

Total count: $\quad 5547$ words

A table of experimental measurements is appended in a separate file, supp.doc, for

Supplemental Material. 


\begin{abstract}
Atomic $\mathrm{Cl}$ was generated by pulsed laser photolysis at $193 \mathrm{~nm}$ of $\mathrm{CCl}_{4}$, and was monitored by time resolved resonance fluorescence in the course of reaction with excess $\mathrm{C}_{2} \mathrm{H}_{2}$, diluted in Ar bath gas at pressures from 13 to 800 mbar. At $288 \mathrm{~K}$ simple pseudo first order kinetics were observed. Over 365-430 K bi-exponential decays were obtained, because of equilibration between the $\beta$-chlorovinyl adduct and the reactants. The ratios of forward and reverse rate constants yield $\Delta_{\mathrm{f}} \mathrm{H}_{298}(\cdot \mathrm{CH}=\mathrm{CHCl})=272.4 \pm 1.3 \mathrm{~kJ} \mathrm{~mol}^{-1}$ via a Third-Law analysis of the carbon-chlorine bond strength. The thermochemistry compares well with that predicted by an initio theory. The effective second-order rate constant was pressure dependent and was analyzed using Troe's unimolecular formalism. Over the whole temperature range the low-pressure limiting value for addition, with Ar bath gas, is given by $k_{0}=4.1 \times 10^{-30}(\mathrm{~T} / 300 \mathrm{~K})^{-2.48} \mathrm{~cm}^{6}$ molecule ${ }^{-2} \mathrm{~s}^{-1}$.
\end{abstract}

Keywords: chlorine, acetylene, chlorovinyl, kinetics, bond strength 


\section{Introduction}

The reaction of ground-state chlorine atoms with acetylene has previously been studied at low to moderate temperatures, in the context of a potential sink for $\mathrm{Cl}$ and/or $\mathrm{C}_{2} \mathrm{H}_{2}$ in the atmosphere [1-8]. That work revealed a pressure dependence of the effective second order rate constant $k_{l}$ so that the reaction can be written as

$$
\mathrm{Cl}+\mathrm{C}_{2} \mathrm{H}_{2} \rightarrow \mathrm{C}_{2} \mathrm{H}_{2} \mathrm{Cl}
$$

where $\mathrm{C}_{2} \mathrm{H}_{2} \mathrm{Cl}$ is an adduct, presumably the $\beta$-chlorovinyl radical. The reaction has been the focus of a fundamental analysis of unimolecular rate theory by Zhu et al. [9], based on the energy transfer mechanism [10]:

$$
\begin{aligned}
& \mathrm{Cl}+\mathrm{C}_{2} \mathrm{H}_{2} \rightarrow \mathrm{C}_{2} \mathrm{H}_{2} \mathrm{Cl}^{*} \\
& \mathrm{C}_{2} \mathrm{H}_{2} \mathrm{Cl}^{*} \rightarrow \mathrm{Cl}+\mathrm{C}_{2} \mathrm{H}_{2} \\
& \mathrm{C}_{2} \mathrm{H}_{2} \mathrm{Cl}^{*}+\mathrm{M} \rightarrow \mathrm{C}_{2} \mathrm{H}_{2} \mathrm{Cl}+\mathrm{M}
\end{aligned}
$$

There is competition between dissociation of the initially excited adduct, and stabilization by collisions with a third body $\mathrm{M}$. At low $[\mathrm{M}]$ the final step is rate determining, and the low-pressure limiting rate constant $k_{0}$ is third order, and depends on the nature of M. In our experiments we employed $\mathrm{M}=\mathrm{Ar}$ as the bath gas. At the low-pressure limit, $k_{1}=$ $k_{0}[\mathrm{M}]$. In general the effective second order rate constant $k_{l}$ is pressure-dependent, and its high-pressure limiting value, $k_{\infty}$, corresponds to the rate constant for initial adduct formation. Areas of uncertainty include the extent of anharmonicity in the adduct, and the C-Cl bond strength within $\mathrm{C}_{2} \mathrm{H}_{2} \mathrm{Cl}$ [9]. Troe has discussed interpolation between the limiting pressure behaviors [11], and we apply his formalism to the fall-off region:

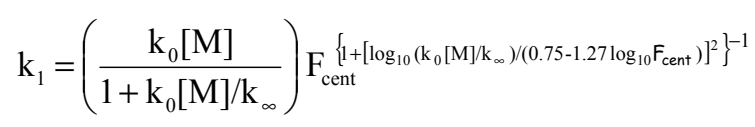


$\mathrm{F}_{\mathrm{cent}}$ is the broadening parameter which allows for both strong and weak collision effects [11]. As can be seen in the work of Kaiser and Wallington [8], because the high-pressure limit has not been reached experimentally, different $\mathrm{F}_{\text {cent }}$ values lead to similarly good fits to the data but to different extrapolations for $k_{\infty}$. Here we make use of ab initio vibrational frequencies at the transition state to define the $\mathrm{F}_{\text {cent }}$ term [11].

Because the $\beta$-chlorovinyl radical can in turn react with $\mathrm{Cl}_{2}$ or acetylene, reaction 1 is a propagation step in the chlorination of acetylene by $\mathrm{Cl}_{2}$ and is part of the mechanism whereby chlorine catalyzes the polymerization of acetylene [12]. Chlorovinyl radicals in general are intermediates in the incineration of chlorinated waste, and $\mathrm{C}_{2} \mathrm{H}_{2} \mathrm{Cl}$ is a product of the oxidation of vinyl chloride, for example by $\mathrm{OH}$ [13]. Although needed for reliable combustion modeling, no experimental data are available for the enthalpies of formation of any chlorovinyl radicals. These have been the subject of prior computational studies $[9,12,14-16]$.

In this work we present kinetic measurements on reaction 1, extended to sufficiently high temperatures for addition to become reversible. This enables determination of the equilibrium constant $\mathrm{K}_{\mathrm{eq}}$, and thus the thermochemistry via a Third Law approach [17]. We also obtained kinetic data in the low-pressure and fall-off regions, where discrepancies in the temperature dependence have been noted between flash-photolysis and relative rate measurements [18]. New ab initio investigations of anharmonic motion within the chlorovinyl radical are described, and the resulting adduct enthalpy and the associated potential energy surface are compared with experiment. 


\section{Experimental method}

Atomic $\mathrm{Cl}$ was generated by pulsed laser photolysis of $\mathrm{CCl}_{4}$ at $193 \mathrm{~nm}$, and monitored by time-resolved resonance fluorescence at 130-140 nm with photon counting and signal averaging. The fluorescence signal is proportional to [Cl], plus a steady background from scattered light within the reactor. Details of the apparatus and technique have been given elsewhere $[19,20]$. Experimental parameters such as $\left[\mathrm{CCl}_{4}\right]$ and the photolysis energy $\mathrm{F}$, together with the beam cross section of approximately $7 \times 8 \mathrm{~mm}^{2}$ and the absorption cross-section of $\mathrm{CCl}_{4}$ [21], were employed to estimate the initial atomic concentration $[\mathrm{Cl}]_{0}$. Low intensities were employed to isolate the primary reaction from secondary processes involving the products of reaction or $\mathrm{CCl}_{4} \mathrm{Or}_{2} \mathrm{H}_{2}$ photolysis. Variation of the average gas residence time inside the reactor, $\tau_{\text {res }}$, checked for any thermal decomposition or mixing effects.

At room temperature, loss of $\mathrm{Cl}$ is dominated by reaction 1, diffusion and any secondary chemistry. We can write

$$
\mathrm{d}[\mathrm{Cl}] / \mathrm{dt}=-k_{l}\left[\mathrm{C}_{2} \mathrm{H}_{2}\right][\mathrm{Cl}]-k_{4}[\mathrm{Cl}]=-k_{p s I}[\mathrm{Cl}]
$$

where, because $\left[\mathrm{C}_{2} \mathrm{H}_{2}\right]>>[\mathrm{Cl}]$, pseudo-first-order kinetics are followed, and are described by the decay coefficient $k_{p s}$. An example of an exponential decay of the fluorescence signal is shown as the inset on Fig. 1. A plot of $k_{p s l}$ vs. $\left[\mathrm{C}_{2} \mathrm{H}_{2}\right]$ should be linear with a slope equal to $k_{l}$, and an example is shown in Fig. 1. Typically five concentrations of $\left[\mathrm{C}_{2} \mathrm{H}_{2}\right]$, from zero to $\left[\mathrm{C}_{2} \mathrm{H}_{2}\right]_{\max }$, were employed for each determination of $k_{1}$. The intercept $k_{4}$ accounts for diffusion (which is effectively first order under our conditions) and any secondary chemistry. 
At elevated temperatures the exothermic equilibrium for chlorovinyl formation becomes less favorable, and its dissociation back to reactants becomes fast enough to be important. We also allow for loss of chlorovinyl by processes which do not regenerate atomic $\mathrm{Cl}$ in the following kinetic scheme:

$$
\begin{aligned}
& \mathrm{Cl}+\mathrm{C}_{2} \mathrm{H}_{2} \rightarrow \mathrm{C}_{2} \mathrm{H}_{2} \mathrm{Cl} \\
& \mathrm{C}_{2} \mathrm{H}_{2} \mathrm{Cl} \rightarrow \mathrm{Cl}+\mathrm{C}_{2} \mathrm{H}_{2} \\
& \mathrm{Cl} \rightarrow \text { diffusion } \\
& \mathrm{C}_{2} \mathrm{H}_{2} \mathrm{Cl} \rightarrow \text { loss }
\end{aligned}
$$

This scheme implies bi-exponential decays for the $\mathrm{Cl}$ atom concentration [22], where

$$
\begin{gathered}
\lambda_{1,2}=-\frac{\left(\mathrm{k}_{1}\left[\mathrm{C}_{2} \mathrm{H}_{2}\right]+\mathrm{k}_{-1}+\mathrm{k}_{5}+\mathrm{k}_{4}\right) \pm \sqrt{\left(\mathrm{k}_{1}\left[\mathrm{C}_{2} \mathrm{H}_{2}\right]+\mathrm{k}_{4}+\mathrm{k}_{-1}+\mathrm{k}_{5}\right)^{2}-4\left(\mathrm{k}_{1} \mathrm{k}_{5}\left[\mathrm{C}_{2} \mathrm{H}_{2}\right]+\mathrm{k}_{4} \mathrm{k}_{-1}+\mathrm{k}_{4} \mathrm{k}_{5}\right)}}{2} \\
{[\mathrm{Cl}]=[\mathrm{Cl}]_{0} \frac{\left(\lambda_{1}+\mathrm{k}_{-1}+\mathrm{k}_{5}\right) \mathrm{e}^{\lambda_{1} \mathrm{t}}-\left(\lambda_{2}+\mathrm{k}_{-1}+\mathrm{k}_{5}\right) \mathrm{e}^{\lambda_{2} \mathrm{t}}}{\lambda_{1}-\lambda_{2}}}
\end{gathered}
$$

An example is shown as the inset in Fig. 2. The data were fitted to the form of eq. (6) by fixing $k_{4}$ at a value obtained from photolysis of a $\mathrm{CCl}_{4} / \mathrm{Ar}$ mixture, and directly adjusting $k_{1}\left[\mathrm{C}_{2} \mathrm{H}_{2}\right], k_{-l}$ and $k_{5}$. A plot of $k_{1}\left[\mathrm{C}_{2} \mathrm{H}_{2}\right]$ vs. $\left[\mathrm{C}_{2} \mathrm{H}_{2}\right]$ should be linear with zero intercept and a slope equal to $k_{l}$, as shown in Fig. 2 .

\section{Kinetics and thermochemistry}

Seventy three measurements are summarized, along with the experimental conditions, in Table S1 of the Supplemental Material. The independence of $k_{l}$ from F and $[\mathrm{Cl}]_{0}$ (in the range $(0.1-10) \times 10^{12}$ molecule $\mathrm{cm}^{-3}$ ) indicates that sufficiently low 
photolysis energies were employed for secondary chemistry to be negligible. Figure 3 shows the data at $288 \mathrm{~K}$, which may be seen to lie in the fall-off region. Previous analysis used a standard value of $\mathrm{F}_{\text {cent }}=0.6$, and for direct comparison we first employ that same value. Fitting to eq. (2) yields $k_{0}=(4.7 \pm 0.1) \times 10^{-30} \mathrm{~cm}^{6}$ molecule $\mathrm{s}^{-1}$ for $\mathrm{M}=\mathrm{Ar}$, and $k_{\infty}$ $=(2.5 \pm 0.2) \times 10^{-10} \mathrm{~cm}^{3}$ molecule $\mathrm{s}^{-1}$. The latter value agrees with the NASA-JPL evaluation [18] of $(2.2 \pm 0.4) \times 10^{-10} \mathrm{~cm}^{3}$ molecule $\mathrm{e}^{-1} \mathrm{~s}^{-1}$. The most comparable prior work is by Brunning and Stief [3], who employed flash lamp photolysis of $\mathrm{CCl}_{4}$ and several bath gases $\mathrm{M}$. Their rate constants for $\mathrm{M}=\mathrm{Ar}$ at $296 \mathrm{~K}$ are ca. a factor of 2 larger than ours. Their $k_{0}$ value with $\mathrm{N}_{2}$ bath gas is also about twice the recommended NASA-JPL [18] value at $300 \mathrm{~K}$ so it seems likely that their work was affected by systematic error. Our own $k_{0}$ for Ar scaled by Brunning and Stief's ratio $k_{0}\left(\mathrm{~N}_{2}\right) / k_{0}(\mathrm{Ar})$ is $6.7 \times 10^{-30} \mathrm{~cm}^{6}$ molecule $\mathrm{s}^{-1}$, in good agreement with the NASA-JPL recommendation for $\mathrm{M}=\mathrm{N}_{2}$ of $(6.4$ $\pm 1.1) \times 10^{-30} \mathrm{~cm}^{6}$ molecule $\mathrm{e}^{-2} \mathrm{~s}^{-1}$.

With the somewhat arbitrary choice of the broadening parameter $\mathrm{F}_{\text {cent }}=0.6$, the values of $k_{0}$ and $k_{\infty}$ discussed so far are essentially fitting parameters. A physically-based evaluation of $\mathrm{F}_{\text {cent }}$ via the temperature dependence of the vibrational partition function of the transition state, as detailed by Troe [11], yields the values summarized in Table 1. Because several collisions with the bath gas may be required to stabilize the initially excited adduct, these "weak collision" effects are taken into account through a collisional efficiency $\beta_{c}[11]$. The influence of weak collisions on $F_{\text {cent }}$ is modest, with $F_{\text {cent }} \propto \beta_{c}^{0.14}$, and here we assume a typical value of $\beta_{\mathrm{c}}=0.4$ for Ar at room temperature [11]. The corresponding average energy transferred in all up and down collisions is $3 \mathrm{~kJ} \mathrm{~mol}^{-1}$, taken here to be independent of temperature. Table 1 lists the corresponding limiting rate 
constants for reaction (1). Above room temperature our measurements are close to the low-pressure limiting regime and do not yield useful new information about $k_{\infty}$. It is the low-pressure limit that will dominate combustion chemistry and, as may be seen from Fig. $4, k_{0}$ decreases with increasing temperature and may be expressed as

$$
k_{0}=(4.1 \pm 0.1) \times 10^{-30}(\mathrm{~T} / 300 \mathrm{~K})^{-2.48 \pm 0.10} \mathrm{~cm}^{6} \text { molecule } \mathrm{s}^{-2}
$$

where the uncertainty in each parameter is $1 \sigma$. Error limits in $k_{0}$ are estimated as around \pm $10 \%$. This temperature dependence is close to the exponent of $-2.1 \pm 1.0$ in the NASAJPL critical review [18], which is weighted towards relative rate measurements, and our results help resolve the discrepancy noted there with earlier flash photolysis measurements.

At elevated temperatures the $\mathrm{Cl}$ atom profiles become sensitive to dissociation of the chlorovinyl adduct back to reactants, or other loss processes for the adduct, so that data for $k_{-1}$ and $k_{5}$ were also obtained. The $k_{5}$ results, listed in Table S1 of the Supplemental Material, were scattered and poorly defined, typically in the range 200-500 $\mathrm{s}^{-1}$ and as large as $1000 \mathrm{~s}^{-1} . \mathrm{k}_{5}$ showed no trend with $\left[\mathrm{C}_{2} \mathrm{H}_{2}\right]$ or the photolysis energy (and so secondary chemistry involving $\mathrm{H}$ or $\mathrm{C}_{2} \mathrm{H}$ is unlikely), but it did increase with pressure. Possibly this loss path is a unimolecular reaction of chlorovinyl, although a high barrier is expected, for example, for isomerization to $\alpha$-chlorovinyl (see below).

The rate of the reverse process (-1) was found to be independent of $\left[\mathrm{C}_{2} \mathrm{H}_{2}\right]$ but, of course, dependent on $[\mathrm{Ar}]$. The average ratio $k_{1} / k_{-1}=K_{\text {eq }}$ at each temperature is given in Table 1. These equilibrium constants, converted to a standard state of unit activity, are plotted in van't Hoff form in Fig. 5, including a minor correction to $\ln K_{e q}$ of around 0.06 equal to $-\left(\Delta \mathrm{S}_{\mathrm{T}}-\Delta \mathrm{S}_{298}\right) / \mathrm{R}+\left(\Delta \mathrm{H}_{\mathrm{T}}-\Delta \mathrm{H}_{298}\right) / \mathrm{RT}[17]$ and derived from ab initio information 
for the adduct (see below) and data for the reactants taken from the NIST-JANAF Tables [23]. The intercept is constrained to equal the computed $\Delta \mathrm{S}_{298} / \mathrm{R}=-11.55$ and the slope equals $-\Delta \mathrm{H}_{298} / \mathrm{R}$. This Third Law analysis yields $\Delta \mathrm{H}_{298}=-75.6 \mathrm{~kJ} \mathrm{~mol}^{-1}$ for reaction (1). Consideration of the uncertainties in $K_{e q}$ implies error limits of about $\pm 1.0 \mathrm{~kJ} \mathrm{~mol}^{-1}$. Combination of the bond dissociation enthalpy with information on $\mathrm{Cl}$ and $\mathrm{C}_{2} \mathrm{H}_{2}$ [23] implies $\Delta_{\mathrm{f}} \mathrm{H}_{298}(\cdot \mathrm{CH}=\mathrm{CHCl})=272.4 \pm 1.3 \mathrm{~kJ} \mathrm{~mol}^{-1}$.

As an example of an application of these results, we note that at above about 800 $\mathrm{K}$ abstraction is faster than addition for the reaction of $\mathrm{OH}$ with chloroethene at $1 \mathrm{~atm}$ pressure [13]. At for example $1000 \mathrm{~K}$ the total abstraction rate constant is predicted to be $5 \times 10^{-12} \mathrm{~cm}^{3}$ molecule $\mathrm{s}^{-1}$, with an $\alpha: \beta$ chlorovinyl product ratio of about 0.4:0.6 [13] The lifetime of $\beta$-chlorovinyl in 1 atm of Ar, based on eq. (7) and our thermochemistry, is estimated as $7 \mu \mathrm{s}$. At $1500 \mathrm{~K}$ this shortens to about $0.5 \mathrm{~ns}$. Thus oxidation of $\mathrm{C}_{2} \mathrm{H}_{3} \mathrm{Cl}$ could lead essentially directly to $\mathrm{Cl}+\mathrm{C}_{2} \mathrm{H}_{2}$.

\section{Computational analysis of $\beta$-chlorovinyl}

We have explored the potential energy surface for reaction (1) using ab initio methods. Calculations were carried out with the Gaussian 03 program [24]. Geometries and frequencies, scaled by a factor of 0.955 [25], were obtained with QCISD/6-311G(d,p) theory. Single point energies at these geometries were then obtained with the CBS-QB3 methodology [26] which approximates an extrapolation of coupled-cluster theory to the complete basis set limit, here adapted to incorporate the QCISD zero-point vibrational energy and a spin-orbit correction of $-3.5 \mathrm{~kJ} \mathrm{~mol}^{-1}$ to the energy of atomic $\mathrm{Cl}$. The geometries of stationary points are shown in Fig. 6, and more details of the calculations 
are listed in Table 2. Figure 7 shows a potential energy diagram, and it may be seen that there is no energy barrier to addition.

The reaction begins by formation of a loose $\mathrm{C}_{2} \mathrm{~V} \pi$ complex between $\mathrm{Cl}$ and $\mathrm{C}_{2} \mathrm{H}_{2}$, structure 2 of Fig. 6, followed by passage through an asymmetric transition state (structure 3 ) where the $\mathrm{Cl}$ atom begins to form a $\sigma$ bond to a single carbon atom, leading to $\beta$-chlorovinyl where the $\mathrm{H}$ atoms are in a trans configuration (structure 4 ). The $1,2 \mathrm{H}$ atom shift needed to create $\alpha$-chlorovinyl (structure 8) passes through transition state structure 7 and has a high barrier. Similar reaction paths involve loose entrance complexes and low-lying transition states have also been proposed in the cases of $\mathrm{Cl}$ atom reactions with $\mathrm{C}_{2} \mathrm{Cl}_{2}$ and $\mathrm{CH}_{2} \mathrm{CCH}_{2}[27,28]$.

There is only a modest barrier for isomerization between cis and trans isomers of $\beta$-chlorovinyl, via structure 5 , and the two species are likely to be in equilibrium. This isomerization occurs via $\mathrm{H}-\mathrm{C}-\mathrm{C}$ bending, which we have explored through relaxed scans at the QCISD level of theory. Figure 8 shows the associated double well potential, and the anharmonic vibrational energy levels were obtained via numerical solution of the Schrodinger equation [29]. These energy levels, together with a harmonic normal mode analysis for the other internal motions, were employed to derive the entropy and thermal corrections for $\beta$-chlorovinyl. We obtain $\mathrm{S}_{298}=270.0 \mathrm{~J} \mathrm{~mol}^{-1} \mathrm{~K}^{-1}$ and $\mathrm{H}_{298}-\mathrm{H}_{0}=12.1 \mathrm{~kJ}$ $\mathrm{mol}^{-1}$. Over $200-1500 \mathrm{~K}$ the heat capacity $\mathrm{C}_{\mathrm{p}}$ may be expressed as $9.10+0.21966 \mathrm{~T}-$ $2.6142 \times 10^{-4} \mathrm{~T}^{2}+1.5406 \times 10^{-7} \mathrm{~T}^{3}-3.47959 \times 10^{-11} \mathrm{~T}^{4}$ in $\mathrm{J} \mathrm{mol}^{-1} \mathrm{~K}^{-1}$. The wavefunction for the lowest energy level of Fig. 8, as expected, is localized at the more stable trans geometry. An intriguing aspect is that most of the amplitude of the wavefunction for the second level is localized at the cis geometry, the third at trans, the fourth at cis, and from 
the fifth level the wavefunctions become delocalized over the whole range of $\mathrm{H}-\mathrm{C}-\mathrm{C}$ angles and the distinction between cis and trans isomers is lost. At room temperature the ratio of Boltzmann-weighted levels yields a cis fraction of $13 \%$, in agreement with the experimental result of $16 \pm 4 \%$ obtained by Zhu et al. [30], who trapped $\beta$-chlorovinyl with $\mathrm{Cl}_{2}$.

Our computed $298 \mathrm{~K}$ bond dissociation enthalpy for $\beta$-chlorovinyl is $78.8 \mathrm{~kJ}$ $\mathrm{mol}^{-1}$, in good accord with the measurement of $75.6 \pm 1.0 \mathrm{~kJ} \mathrm{~mol}^{-1}$. Prior calculations include a composite approximation to $\operatorname{CCSD}(\mathrm{T}) / 6-311+\mathrm{G}(2 \mathrm{df}, 2 \mathrm{p})$ by Resende et al. [12] who obtained $65.4 \mathrm{~kJ} \mathrm{~mol}^{-1}$, and the G2 result from Zhu et al. [9] who obtained $70.5 \mathrm{~kJ}$ $\mathrm{mol}^{-1}$ (after conversion to $298 \mathrm{~K}$ ). This latter result is very close to experiment, although we find the more sophisticated G3 method [31] (which like our calculation includes a spin-orbit correction to the $\mathrm{Cl}$ atom energy) yields a slightly less accurate result of 76.7 $\mathrm{kJ} \mathrm{mol}^{-1}$. These values are somewhat smaller than the results of computations by Bryukov et al. for the $\mathrm{Cl}_{-} \mathrm{C}_{2} \mathrm{Cl}_{2}$ bond dissociation energy, which yielded values in the range 95-115 $\mathrm{kJ} \mathrm{mol}^{-1}$ [27]. This difference may reflect stabilization of the radical center in vinyl by halogen atoms, as proposed by Srinivas and Schwartz [16]. Now that the enthalpy of formation of one chlorovinyl radical has been measured, this information can be employed in isodesmic reactions to obtain reliable information about other chlorovinyl species. 


\section{Conclusions}

The kinetics of chlorine atom addition to acetylene have been measured over 288

$-430 \mathrm{~K}$. The temperature dependence of the low-pressure limiting rate constant is in line with lower temperature data obtained via relative rate measurements. Observation of equilibration yields the carbon-chlorine bond dissociation enthalpy of the $\beta$-chlorovinyl radical and the first direct determination of its enthalpy of formation. Ab initio results are in good agreement with this measurement, and analysis of the anharmonic $\mathrm{H}-\mathrm{C}-\mathrm{C}$ bending mode is in good accord with previous experiments that determined the cis:trans ratio in $\beta$-chlorovinyl.

\section{Acknowledgments}

We thank Steven Hong, Albert Vu, B.J. Wion and Zhenmou Yue for assistance with some of the experiments. This work was supported by the Robert A. Welch Foundation (Grant B-1174) and the UNT Faculty Research Fund. Computations were carried out at the National Center for Supercomputing Applications (Grant CHE000015N), on the UNT Research Cluster, and on facilities purchased with funds from the National Science Foundation (Grant CHE-0342824). 


\section{References}

[1] J. Poulet, J. Barassin, G.L. Bras, J. Combourieu, Bull. Soc. Chim. Fr. 1 (1973) 1.

[2] F.S.C. Lee, F.S. Rowland, J. Phys. Chem. 81 (1977) 684.

[3] J. Brunning, L.J. Stief, J. Chem. Phys. 83 (1985) 1005.

[4] R. Atkinson, S. Aschmann, Int. J. Chem. Kinet. 17 (1985) 33.

[5] T.J. Wallington, L.M. Skewes, W.O. Siegl, J. Photochem. Photobiol. A 45 (1988) 167.

[6] T.J. Wallington, J.M. Andino, I. Lorkovic, E.W. Kaiser, G. Marston, J. Phys. Chem. 94 (1990) 3644.

[7] E.W. Kaiser, Int. J. Chem. Kinet. 24 (1992) 179.

[8] E.W. Kaiser, T.J. Wallington, J. Phys. Chem. 100 (1996) 4111.

[9] L. Zhu, W. Chen, W.L. Hase, E.W. Kaiser, J. Phys. Chem. 97 (1993) 311.

[10] K.A. Holbrook, M.J. Pilling, S.H. Robertson, Unimolecular Reactions. Wiley, Chichester, 1996.

[11] J. Troe, J. Phys. Chem. 83 (1979) 114.

[12] S.M. Resende, J.R. Pliego, Jr., W.B. De Almeida, J. Chem. Soc., Faraday Trans. 94 (1998) 2895.

[13] L. Zhu, J.W. Bozzelli, W.-P. Ho, J. Phys. Chem. A 103 (1999) 7800.

[14] J.-F. Riehl, K. Morokuma, J. Chem. Phys. 100 (1994) 8976.

[15] C. Galli, A. Guanieri, H. Koch, P. Mencarelli, Z. Rappoport, J. Org. Chem. 62 (1997) 4072.

[16] G.N. Srinivas, M. Schwartz, J. Mol. Struct. Theochem (in press). 
[17] I.J. Kalinovski, D. Gutman, L.N. Krasnoperov, A. Goumri, W.-J. Yuan, P. Marshall, J. Phys. Chem. 98 (1994) 9551.

[18] S.P. Sander, R.R. Friedl, D.M. Golden, M.J. Kurylo, R.E. Huie, V.L. Orkin, G.K. Moortgat, A.R. Ravishankara, C.E. Kolb, M.J. Molina, E.J. Finlayson-Pitts, Chemical Kinetics and Photochemical data for Use in Stratospheric Modeling. Evaluation Number 14. JPL, Pasadena, 2003.

[19] Y. Shi, P. Marshall, J. Phys. Chem. 95 (1991) 1654.

[20] L. Ding, P. Marshall, J. Phys. Chem. 96 (1992) 2197.

[21] A. Hanf, A. Läuter, H.-R. Volpp, Chem. Phys. Lett. 368 (2003) 445.

[22] Y.V. Ahyens, J.M. Nicovich, M.L. McKee, P.H. Wine, J. Phys. Chem. A 101 (1997) 9382.

[23] M.W. Chase, Jr. (Ed.), NIST-JANAF Thermochemical Tables. American Chemical Society and the American Institute of Physics, Woodbury, N. Y., 1998.

[24] M.J. Frisch, G.W. Trucks, H.B. Schlegel, G.E. Scuseria, M.A. Robb, J.R. Cheeseman, J.A. Montgomery, Jr., T. Vreven, K.N. Kudin, J.C. Burant, J.M. Millam, S.S. Iyengar, J. Tomasi, V. Barone, B. Mennucci, M. Cossi, G. Scalmani, N. Rega, G.A. Petersson, H. Nakatsuji, M. Hada, M. Ehara, K. Toyota, R. Fukuda, J. Hasegawa, M. Ishida, T. Nakajima, Y. Honda, O. Kitao, H. Nakai, M. Klene, X. Li, J.E. Knox, H.P. Hratchian, J.B. Cross, C. Adamo, J. Jaramillo, R. Gomperts, R.E. Stratmann, O. Yazyev, A.J. Austin, R. Cammi, C. Pomelli, J.W. Ochterski, P.Y. Ayala, K. Morokuma, G.A. Voth, P. Salvador, J.J. Dannenberg, V.G. Zakrzewski, S. Dapprich, A.D. Daniels, M.C. Strain, O. Farkas, D.K. Malick, A.D. Rabuck, K. Raghavachari, J.B. Foresman, J.V. Ortiz, Q. Cui, A.G. 
Baboul, S. Clifford, J. Cioslowski, B.B. Stefanov, G. Liu, A. Liashenko, P. Piskorz, I. Komaromi, R.L. Martin, D.J. Fox, T. Keith, M.A. Al-Laham, C.Y. Peng, A. Nanayakkara, M. Challacombe, P.M.W. Gill, B. Johnson, W. Chen, M.W. Wong, C. Gonzalez, J.A. Pople, Gaussian 03. Gaussian, Wallingford, CT, 2004.

[25] P. Marshall, G.N. Srinivas, M. Schwartz, J. Phys. Chem. A 109 (2005) 6371.

[26] J.A. Montgomery, Jr., M.J. Frisch, J.W. Ochterski, G.A. Petersson, J. Chem. Phys. 110 (1999) 2822.

[27] M.G. Bryukov, S.A. Kostina, V.D. Knyazev, J. Phys. Chem. A 107 (2003) 6574.

[28] A.A. Shestov, K.V. Popov, V.D. Knyazev, J. Phys. Chem. A 109 (2005) 8149.

[29] R.D. Johnson, III, FGH1D Program (1999) see http://www.nist.gov/compchem/johnson/fgh/fgh1d.html.

[30] T. Zhu, G. Yarwood, J. Chen, H. Niki, J. Phys. Chem. 98 (1994) 5065.

[31] L.A. Curtiss, K. Raghavachari, P.C. Redfern, V. Rassolov, J.A. Pople, J. Chem. Phys. 109 (1998) 7764. 
Table 1. Computed broadening parameter, low- and high-pressure limiting rate constants and the equilibrium constant for $\mathrm{Cl}+\mathrm{C}_{2} \mathrm{H}_{2}$ addition. Uncertainties are statistical only and represent one standard deviation.

\begin{tabular}{ccccc}
\hline $\mathrm{T} / \mathrm{K}$ & $\mathrm{F}_{\text {cent }}^{\mathrm{a}}$ & $\mathrm{k}_{0} / 10^{-30} \mathrm{~cm}^{6}$ molecule ${ }^{-1} \mathrm{~s}^{-1}$ & $\begin{array}{c}\mathrm{k}_{\infty} / 10^{-11} \mathrm{~cm}^{3} \\
\text { molecule } \mathrm{s}^{-1}\end{array}$ & $\begin{array}{c}\mathrm{K}_{\mathrm{eq}} / 10^{-15} \mathrm{~cm}^{3} \\
\text { molecule }\end{array}$ \\
\hline 288 & 0.713 & $4.50 \pm 0.06$ & $17.7 \pm 0.9$ & - \\
365 & 0.658 & $2.34 \pm 0.15$ & $22.8 \pm 13.2$ & $15.9 \pm 5.4$ \\
387 & 0.644 & $2.34 \pm 0.12$ & $5.8 \pm 1.3$ & $6.17 \pm 1.66$ \\
400 & 0.636 & $2.00 \pm 0.08$ & $4.9 \pm 0.7$ & $4.41 \pm 0.72$ \\
415 & 0.628 & $1.67 \pm 0.11$ & $8.8 \pm 3.6$ & $2.69 \pm 0.84$ \\
430 & 0.620 & $1.68 \pm 0.14$ & $1.8 \pm 0.6$ & $1.34 \pm 0.32$ \\
\hline
\end{tabular}

${ }^{a}$ Over $200-2000 \mathrm{~K}, \mathrm{~F}_{\text {cent }}$ can be expressed as $0.422+0.578 \exp (-\mathrm{T} / 410 \mathrm{~K})$. 
Table 2. CBS-QB3 energies and QCISD/6-311G(d,p) vibrational frequencies for stationary points on the $\mathrm{Cl}+\mathrm{C}_{2} \mathrm{H}_{2}$ potential energy surface, numbered as in Fig. 6 .

\begin{tabular}{ccc}
\hline Structure & Energy, au & Frequencies scaled by $0.955, \mathrm{~cm}^{-1}$ \\
\hline 1 & -77.188796 & $550(2), 738(2), 1932,3285,3378$ \\
2 & -536.878210 & $76,80,545,558,740,742,1924,3279,3373$ \\
3 & -536.882088 & $320 \mathrm{i}, 195,606,642,743,817,1813,3260,3336$ \\
4 & -536.902130 & $348,{ }^{\mathrm{b}} 630,680,820,832,1208,1557,3093,3156$ \\
5 & -536.897784 & $595 \mathrm{i}, 388,612,663,746,1199,1572,3040,3298$ \\
6 & -536.900196 & $375,621,634,759,852,1206,1563,3032,3151$ \\
7 & -536.832437 & $2021 \mathrm{i}, 126,375,501,567,717,1674,2292,3125$ \\
8 & -536.908003 & $345,523,702,830,982,1348,1614,2997,3100$
\end{tabular}

${ }^{\mathrm{a}}$ For $0 \mathrm{~K}$. Includes QCISD/6-311G(d,p) zero-point energy. $1 \mathrm{au} \approx 2625.5 \mathrm{~kJ} \mathrm{~mol}^{-1}$. The value for $\mathrm{Cl}$ atom, including spin-orbit coupling, is $-459.684958 \mathrm{au}$.

${ }^{\mathrm{b}}$ Replaced by anharmonic $\mathrm{H}-\mathrm{C}-\mathrm{C}$ bending for thermochemistry above $0 \mathrm{~K}$. 


\section{Figure captions}

Fig. 1 Plot of $k_{p s l}$ vs. $\left[\mathrm{C}_{2} \mathrm{H}_{2}\right]$ at $288 \mathrm{~K}$ and 28 mbar Ar pressure. The inset shows the exponential decay of $[\mathrm{Cl}]$ at $\left[\mathrm{C}_{2} \mathrm{H}_{2}\right]=1.9 \times 10^{14}$ molecule $\mathrm{cm}^{-3}$.

Fig. 2 Plot of $k_{1}\left[\mathrm{C}_{2} \mathrm{H}_{2}\right]$ vs. $\left[\mathrm{C}_{2} \mathrm{H}_{2}\right]$ at $400 \mathrm{~K}$ and 277 mbar Ar pressure. The inset shows the bi-exponential decay of $[\mathrm{Cl}]$ at $\left[\mathrm{C}_{2} \mathrm{H}_{2}\right]=1.3 \times 10^{15}$ molecule $\mathrm{cm}^{-3}$.

Fig. 3 Fall-off of observed second-order rate constant for $\mathrm{Cl}+\mathrm{C}_{2} \mathrm{H}_{2}$ with increasing bath gas density.

Fig. 4 Temperature dependence of the low-pressure limiting rate constant for $\mathrm{Cl}+\mathrm{C}_{2} \mathrm{H}_{2}$.

Fig. 5 van't Hoff plot of $K_{e q}$ for $\mathrm{Cl}$ addition to $\mathrm{C}_{2} \mathrm{H}_{2}$.

Fig. 6 Planar geometries of stationary points on the potential energy surface for $\mathrm{Cl}+$ $\mathrm{C}_{2} \mathrm{H}_{2}$ derived via QCISD/6-311G(d,p) calculations. Distances are in $10^{-10} \mathrm{~m}$ and angles in degrees. 1 acetylene, 2 loose entrance complex, 3 addition transition state, 4 trans $\beta$ chlorovinyl, 5 transition state for cis/trans isomerization, 6 cis $\beta$-chlorovinyl, 7 transition state for $\alpha / \beta$-chlorovinyl isomerization, $8 \alpha$-chlorovinyl.

Fig. 7 Potential energy diagram for $\mathrm{Cl}+\mathrm{C}_{2} \mathrm{H}_{2}$ computed with $\mathrm{CBS}-\mathrm{QB} 3$ theory.

Fig. 8 Potential energy for $\mathrm{H}-\mathrm{C}-\mathrm{C}$ bending in $\beta$-chlorovinyl computed with QCISD/6-311G(d,p) theory, and anharmonic energy levels. Zero angle is linear H-C-C, and positive angles correspond to trans and negative to cis. 


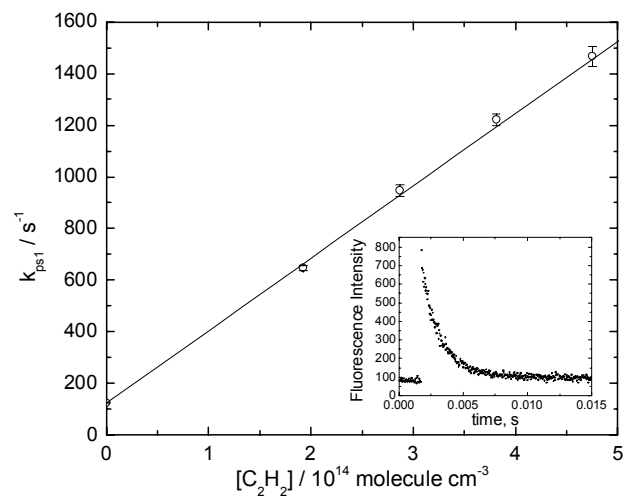

Fig. 1 Plot of $k_{p s I}$ vs. $\left[\mathrm{C}_{2} \mathrm{H}_{2}\right]$ at $288 \mathrm{~K}$ and $28 \mathrm{mbar}$ Ar pressure. The inset shows the exponential decay of $[\mathrm{Cl}]$ at $\left[\mathrm{C}_{2} \mathrm{H}_{2}\right]=1.9 \times 10^{14}$ molecule $\mathrm{cm}^{-3}$. 


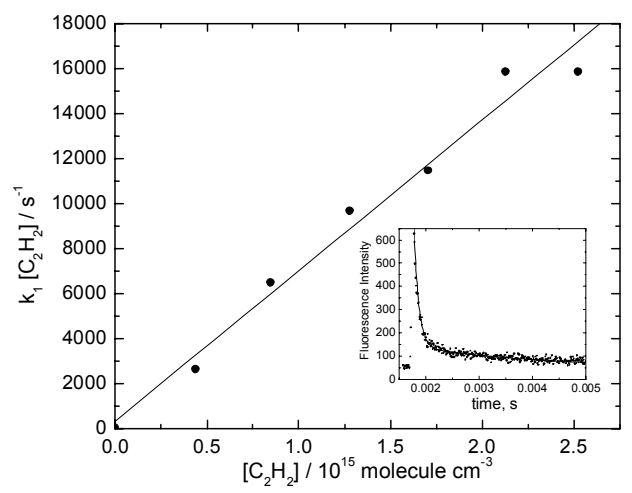

Fig. 2 Plot of $k_{1}\left[\mathrm{C}_{2} \mathrm{H}_{2}\right]$ vs. $\left[\mathrm{C}_{2} \mathrm{H}_{2}\right]$ at $400 \mathrm{~K}$ and 277 mbar Ar pressure. The inset shows the bi-exponential decay of $[\mathrm{Cl}]$ at $\left[\mathrm{C}_{2} \mathrm{H}_{2}\right]=1.3 \times 10^{15}$ molecule $\mathrm{cm}^{-3}$. 


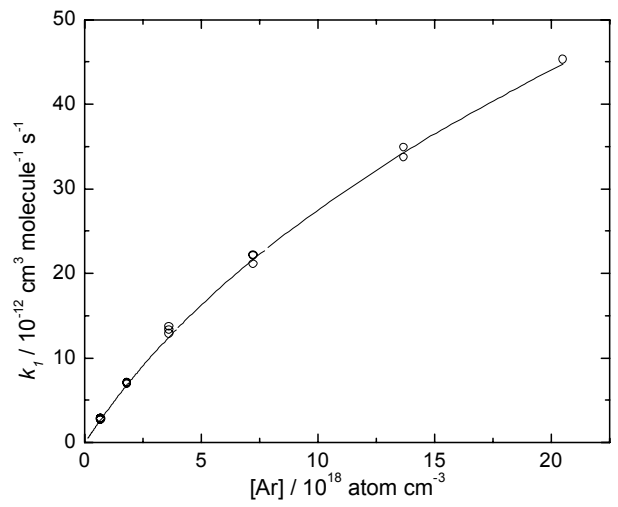

Fig. 3 Fall-off of observed second-order rate constant for $\mathrm{Cl}+\mathrm{C}_{2} \mathrm{H}_{2}$ with increasing bath gas density. 


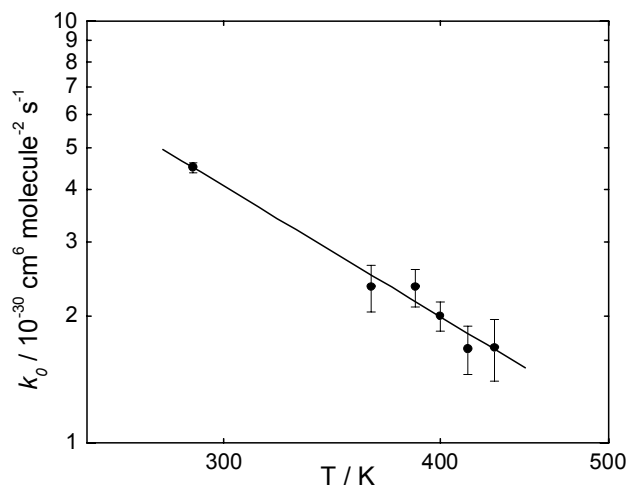

Fig. 4 Temperature dependence of the low-pressure limiting rate constant for $\mathrm{Cl}+\mathrm{C}_{2} \mathrm{H}_{2}$. 


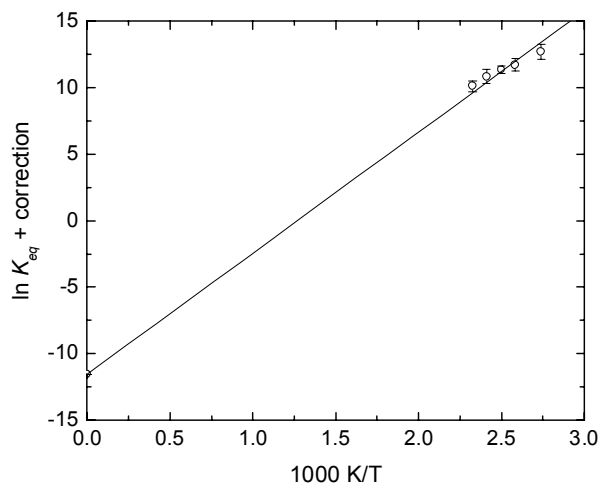

Fig. 5 van't Hoff plot of $K_{e q}$ for $\mathrm{Cl}$ addition to $\mathrm{C}_{2} \mathrm{H}_{2}$. 
1 .

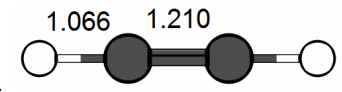

2 .

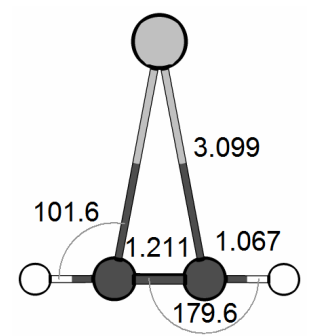

3 .

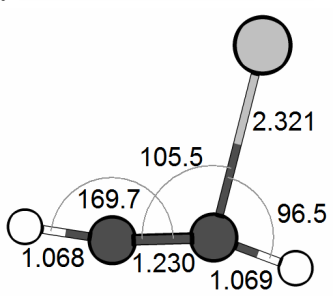

4.

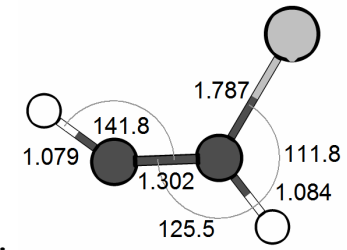

5

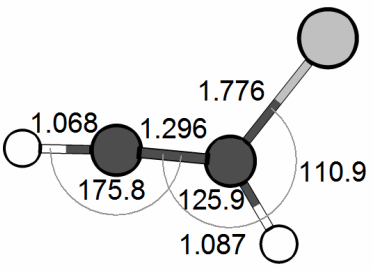

6.

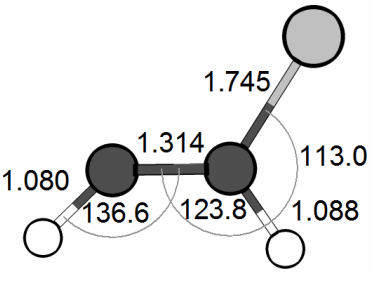

7.

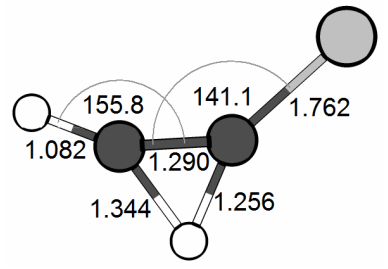

8 .

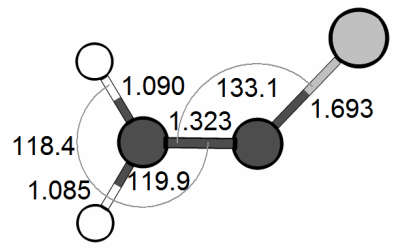

Fig. 6 Planar geometries of stationary points on the potential energy surface for $\mathrm{Cl}+$ $\mathrm{C}_{2} \mathrm{H}_{2}$ derived via QCISD/6-311G(d,p) calculations. Distances are in $10^{-10} \mathrm{~m}$ and angles in degrees. 1 acetylene, 2 loose entrance complex, 3 addition transition state, 4 trans $\beta$ chlorovinyl, 5 transition state for cis/trans isomerization, 6 cis $\beta$-chlorovinyl, 7 transition state for $\alpha / \beta$-chlorovinyl isomerization, $8 \alpha$-chlorovinyl. 


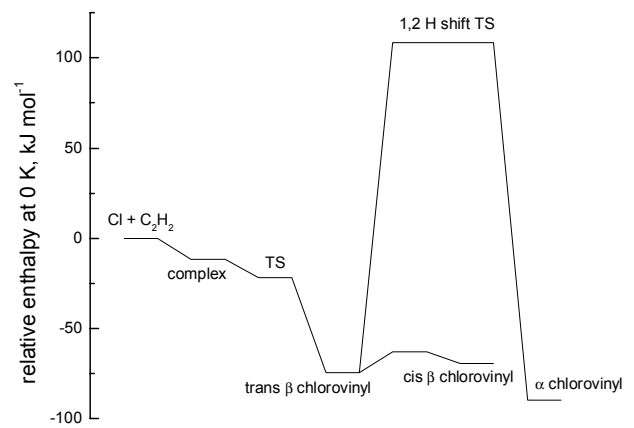

Fig. 7 Potential energy diagram for $\mathrm{Cl}+\mathrm{C}_{2} \mathrm{H}_{2}$ computed with $\mathrm{CBS}-\mathrm{QB} 3$ theory. 


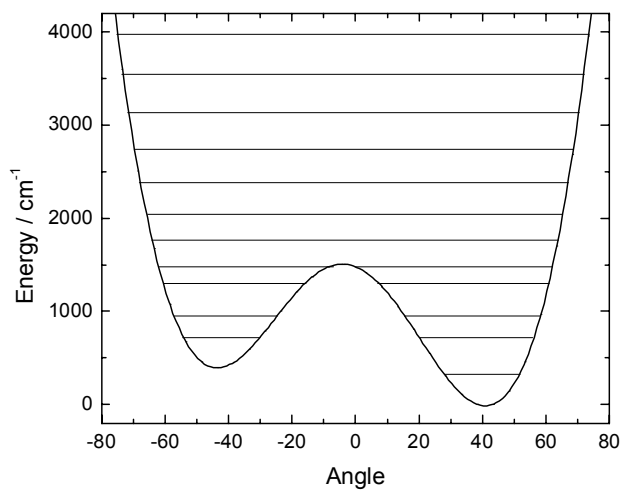

Fig. 8 Potential energy for $\mathrm{H}-\mathrm{C}-\mathrm{C}$ bending in $\beta$-chlorovinyl computed with

QCISD/6-311G(d,p) theory, and anharmonic energy levels. Zero angle is linear H-C-C, and positive angles correspond to trans and negative to cis. 